means of gaining time in electrolysis, it is, nevertheless, possible that some analysts who wish to avoid the trouble involved in effecting mechanical circulation may find the method convenient. At least it is of interest theoretically, in that it demonstrates the gain which may be made by adjusting two of the essential conditions in the most favorable way.

In conclusion, the contents of the paper may be summarized as follows:

The consideration of the conditions necessary for speed in quantitative electrolytic precipitation shows that among the essential ones are the concentration of the solution and the area of the electrode. In the method described, these conditions are made as favorable as possible by concentrating the electrolyte and placing it between two large surfaces in a thin film, such as the annular space between two crucibles separated by a tripod-like device of thin glass rod. Copper was the metal used to test this apparatus. As the concentration of the electrolyte diminishes during the electrolysis, the current strength is diminished, either in steps by the operator, or automatically by employing a single storage cell without resistance. The time required for complete precipitation is inversely proportional to the concentration of the solution, if the cathode surface is unchanged.

\title{
THE ELECTROLYTIC PREPARATION OF CHLOROFORM FROM ACETONE.
}

BY J, E, TEEI'LE.

Received March 4, r904.

IN A recent article a method was given by which almost the theoretical yield of iodoform could be obtained by the electrolysis of a potassium iodide solution in the presence of acetone. No diaphragm was necessary, the essential feature being the gradual addition of a substance such as hydrochloric acid, hydriodic acid, or still better, iodine, to neutralize the excess of potassium hydroxide as fast as it formed. The temperature was kept below $25^{\circ}$, the electrolyte was thoroughly stirred, a high current density used at the cathode and a comparatively low current density at the anode. In short, the aim was to keep the conditions always favorable for the production of a maximum amount of hypoiodite.

1 I'his Journal, 26,170 (1904). 
It will be remembered that Schering's patent covered the electrolytic preparation of chloroform as well as bromoform and iodoform, from alcohol, aldehyde or acetone; but, so far as I know, there is no statement in chemical literature that chloroform has really been made electrolytically from any of these. In fact, Elbs and $\mathrm{Her}^{2}$ could not make it from alcohol. Nevertheless, it was reasonable to suppose that it could be made rather easily from acetone, and that the method which had been used for iodoform could be applied in nearly all details to the preparation of chloroform. This has been found to be the case. The present paper records some of the details regarding the preparation of chloroform by this method.

Assuming the problem to be the same as that presented in the case of iodoform, the solution of it consisted simply in electrolyzing a solution of a chloride in the presence of acetone under conditions that would continuously give the greatest possible yield of hypochlorite. These conditions are now quite well known from the work of Oettel, Förster, and others, the most important ones for our purpose being a temperature below $25^{\circ}$, a solution containing no alkali or as little as possible, a high current density at the cathode and a comparatively low one at the anode.

Preliminary experiments showed that the electrolysis of a 20 per cent. solution of potassium chloride or sodium chloride, containing acetone, for 10 to 15 ampere-hours at $15^{\circ}$ to $20^{\circ}$ does give small amounts of chloroform. By distilling the electrolyte with steam a layer of perhaps I cc. of chloroform is obtained in the distillate, provided evaporation has been prevented during the electrolysis and only a small amount (not over $5 \mathrm{cc}$.) of acetone has been added. Still better, using only roo cc. of electrolyte and only I cc. of acetone, a small layer of chloroform is obtained in the distillate after only 2 or 3 ampere-hours; but no simple method suggested itself by which even an approximate determination of the chloroform could be made in the presence of the acetone. Consequently, it was decided to follow the progress of electrolysis by indirect determinations of the chloroform, for this purpose making use of the amount of alkali set free in the chloroform production.

\footnotetext{
1 D. R. P. 29,77r, March 7, 1884; Friedländer: "Fortschritte der Theerfarbenfabrikation," I, 576 .

2 Zischr. Elektrochem., 4, 118.
} 
When an electric current is passed through a solution of sodium chloride, the sodium set free at the cathode reacts with water to form sodium hydroxide, and this latter then combines with the chlorine liberated at the anode to form chloride, hypochlorite, chlorate or perchlorate; also, the chlorine may decompose water, forming hydrochloric and hypochlorous acids. But in all these reactions the solution, as a whole, remains neutral, ${ }^{1}$ provided there is thorough stirring, so that no chlorine gas escapes. If acetone is adced to the solution, however, most of the hypochlorite reacts with it, possibly as follows:

$$
\begin{aligned}
& 6 \mathrm{NaOH}+6 \mathrm{Cl}=3 \mathrm{NaOCl}+3 \mathrm{NaCl} \\
& 3 \mathrm{NaOCl}_{3} \mathrm{CH}_{3} \mathrm{COCH}=\mathrm{CCl}_{3} \mathrm{COCH}_{3}+3 \mathrm{NaOH} \\
& \mathrm{CCl}_{3} \mathrm{COCH} \mathrm{COCH}_{3}+\mathrm{NaOH}=\mathrm{CHCl}_{3}+\mathrm{NAC}_{2} \mathrm{H}_{3} \mathrm{O}_{2}
\end{aligned}
$$

so that for every gram-molecule of chloroform produced, 2 grammolecules of sodium hydroxide remain in solution, and from a titration of the alkalinity of the solution the amount of chloroform formed may be determined.

This, of course, assumes that chloroform is the only product of the reaction; there are small quantities of other chlorine substitution products formed, so it would be more nearly correct to say that the amonnt of alkali present indicates the amount of current action which has affected the acetone, as opposed to that which has caused chlorate formation, reduction of hypochlorite, water decomposition liberating oxygen and other side reactions. The amount of alkali does not, however, measure the total current efficiency in the direction of chloroform formation, for if only small amounts of acetone are present, sodium hypochlorite may still be detected in the solution several hours after the electrolysis has ceased. Since this hypochlorite can react with the acetone to form more chloroform and liberate more alkali, it must also be taken into account in determining the total current efficiency.

To determine this total amount of current action directed toward the formation of chloroform three methods were tried: First, to a definite portion of the electrolyte an excess of acetone was added. The mixture was allowed to stand a few minutes and then the alkali present was determined by titration, using phenolphthalein as indicator; second, to a definite portion potassium iodide solution was added and, as soon as the iodine color

1 A 15 per cent. sodium chloride solution electrolyzed one homr at a amperes was not alkaline to trinitrobenzene. 
had disappeared, the alkali was determined as before. In either case one-half the number of gram-molecules of alkali found represents the gram-molecules of chloroform produced. In the third method, which seemed preferable to either of the preceding, the amount of hypochlorite was determined in one portion by acidifying, adding potassium iodide, and titrating with thiosulphate, and the alkali present was determined in another portion by titrating directly, using trinitrobenzene as indicator. One-third the amount of hypochlorite plus one-half the amount of alkali in gram-molectles represents the gram-molecules of chloroform.

It was by no means easy to find an indicator suitable for use in titrating the alkali in the last method. Trinitrobenzene was finaaly selected. It is colorless in acid solution, blood-red in alkaline, and is scarcely at all effected by chlorine or hypochlo rites, but if left for a short time in a solution containing much alkali, it becomes permanently colored; hence the first part of the titration should be performed rather rapidly.

The following was found to be a convenient way of arranging an experiment to determine the amounts of chloroform produced and to show how the accumulation of alkali, if allowed to proceed, greatly decreased the yield. A large cylindrical dish provided with an efficient stirring apparatus and cooled by running water serves as a bath; into this $700 \mathrm{cc}$. water, I 20 grams sodium chloride and $25 \mathrm{cc}$. acetone (if the stirring evaporates much acetone, more may be added at regular intervals) are placed and stirred till the salt has dissolved. The anode is a platinum foil of about $75 \mathrm{sq} . \mathrm{cm}$., placed at one side of the dish; a platinum wire dipping just below the surface of the solution in the middle or opposite side of the dish acts as cathode. An ammeter and voltameter are connected in circuit, the solution is kept at a temperature of about $20^{\circ}$, and a current of 3 to 4 amperes passed through. At tenminute intervals three $5 \mathrm{cc}$. portions are removed from the solution with pipettes. To the first a few drops of alcoholic trinitrobenzene solution are added and the solution titrated at once with tenthnormal acid till just colorless. The second is acidified, a little potassium iodide solution added and then it is titrated with tenthnormal thiosulphate. To the third a little potassium iodide solution is added and, as soon as the iodoform has precipitated, a drop of phenolphthalein is added, and the mixture is titrated with tenth-normal acid till colorless. 
From the first titration the total amount of alkali present in the solution is computed; from the second, the amount of hypochlorite which has not yet reacted with acetone is determined; two-thirds the number of cubic centimeters of thiasulphate required represents the amount of tenth-normal alkali, which would have been formed had all the hypochlorite had time to react with the acetone. The third serves as a check and the number of cubic centimeters required for it should be aproximately two-thirds the thiosulphate used in the second, plus all the acid used in the first titration; this sum represents the total current action in the direction of chloroform formation. If no reactions occurred during the electrolysis, but the formation of hypochlorite and conversion of this into chloroform, then $12.43 \mathrm{cc}$. of normal alkali would be formed in the solution for each ampere-hour. The ratio between the amount actually found in the third titration (or the frist and second combined) and the amount computed (I2.43 times the number of ampere-hours) is takets to represent the current efficiency. During the first few minutes this efficiency is 80 to go per cent., but as the alkalinity of the solution increases it falls rapidly, so that during the fifth ampere-hour it is less than 40 per cent. and during the twelfth less than io per cent.

If now another experiment is arranged like this in all details except that after each titration with trinitrobenzene as indicator, there is added to the electrolyte nearly enough normal ( $2 \mathrm{~N}$ or $3 \mathrm{~N}$ ) hydrochloric acid to neutralize the free alkali found, the current efficiency is very much increased, the average found for the first 8 ampere-hours being nearly 80 per cent. These experiments were made without the addition of $\mathrm{CaCl}_{2}$ or $\mathrm{K}_{2} \mathrm{CrO}_{4}$ to the electrolyte, either of which would have increased the efficiency, but would, at the same time, have interfered with the titrations. Platinized electrodes, instead of the platinum ones used, might have increased the yield without any accompanying disadvantage.

Another method used to follow the course of the chloroform formation was to electrolyze about $100 \mathrm{cc}$. of a 20 per cent. salt solution containing 2 to $5 \mathrm{cc}$. of acetone and a few drops of an acetone solution of trinitrobenzene. Thorough stirring was accomplished either in the ustal manner or with a rotating anode, and a strong standard ( 2 to 3 times normal) solution of hydro- 
chloric acid was added from a burette, drop by drop, as needed to keep the electrolyte nearly neutral. If care is used to avoid an excess of alkali, the indicator works very satisfactorily. When the electrolysis is ended, however, the amount of acid used indicates only that portion of the reaction, which is entirely completed, and does not take into account the hypochlorite still present in solution. To determine the total current efficiency, as in the previous experiment, this hypochlorite must be determined directly, or potassium iodide solution or an excess of acetone must be added and a determination made of the amount of alkali set free. In this way the yield of chloroform is, as before, usually found to be nearly 80 per cent. of the theoretical yield.

As was previously stated, the hypochlorite reacts with acetone much slower than does hypoiodite. While hypochlorite may be detected for several hours in the presence of acetone (possibly the reaction product, chloroform, must also be present), if we add a little potassium iodide solution both hypochlorite and hypoiodite disappear within a minute. The rapidity with which the hypochlorite reacts is, of course, influenced by the amount of acetone present, the degree of alkalinity of the solution, and the temperature. In the experiments quoted above, using a large amount of solution and keeping the electrolyte neutral, the concentration of sodium hypochlorite did not vary far from 2 grams per liter. While possibly not accurate enough for use in determining the reaction velocity of chloroform-formation, the following experiment gives an approximate idea of the speed. Pass a current of I to 2 ampere-hours through I $50 \mathrm{cc}$. of a 25 per cent. sodium chloride solution containing $5 \mathrm{cc}$. acetone and a little trinitrobenzene indicator; the bath is to be placed in running water at fairly constant temperature and stirred thoroughly. Add standard hydrochloric acid to the solution from time to time, as needed to neutralize the sodium hydroxide formed and when the electrolysis ends have the solution just neutral. Use a small portion to determine the amount of hypochlorite present, and continue the stirring and addition of acid to the rest as the red color due to alkali reappears. It can be followed quite well usually for about an hour, then proceeds quite slowly, but the red color will still reappear after four or five hours.

While the above methods of electrolyzing in open dishes, neu- 
tralizing the alkali formed by additions of hydrochloric acid, and following the reaction by titration, either of the whole solution or of small portions, are quite satisfactory for determining the most favorable conditions and the efficiency, they obviously are not adapted to the isolation of the chloroform prepared. If we cover the dishes as closely as possible, chloroform may be distilled from the solutions after electrolysis, but better results can usually be obtained as follows:

In an ordinary cylinder of I 50 to $200 \mathrm{cc}$. capacity place $100 \mathrm{cc}$. water, 20 grams sodium chloride and $4 \mathrm{cc}$. acetone; a platinum cylinder serves as anode and a platinum wire as cathode; close the vessel with a cork connected with a reflux condenser, cool the apparatus with running water and electrolyze, passing in a slow stream of chlorine as needed to neutralize the alkali, anode current density about 6 amperes per sq. Im. or less. After 8 to ro ampere hours a small layer of chloroform may be removed from the hottom of the electrolyte by a pipettc and more may be obtained by distilling the solution with steam. The amount of chloroform obtained, as pointed out, does not represent the whole current action in that direction, nor is it the whole of the chloroform actually formed, for a considerable part is still held in solution by the acetone; but if the process were run continuously on an industrial scale there would be no loss from either of these sources.

Before the electrolytic work described above was begun, a few experiments were made concerning the action of chlorine on solt1tions of sodium, potassium and calcium hydroxides containing acetone. The first two gave rather unsatisfactory yields of chloroform, due to chlorate formation, but calcium hydroxide gave quite good results. For example 9.3 grams of pure lime were slaked, suspended in $75 \mathrm{cc}$. water, $7 \mathrm{cc}$. acetone added, and a slow current of chlorine passed through. The vessel containing the mixture was kept cool and shaken thoroughly at frequent intervals. A layer of $4.4 \mathrm{cc}$. chloroform separated and $0.4 \mathrm{cc}$. more could be distilled off with steam, making $4.8 \mathrm{cc}$. or about 7.2 grams actually separated from the solution; computed, 9.9 grams from the equation,

$$
4 \mathrm{CaO}+\mathrm{I} 2 \mathrm{Cl}+{ }_{2} \mathrm{C}_{3} \mathrm{H}_{5} \mathrm{O}={ }_{3} \mathrm{CaCl}_{2}+\mathrm{Ca}\left(\mathrm{C}_{2} \mathrm{H}_{33} \mathrm{O}_{2}\right)_{2}+2 \mathrm{CHCl}_{3} \text {. }
$$

This would suggest electrolysis of a calcium chloride solution in 
the presence of acetone as the best method of forming chloroform, if some way were found to overcome the high resistance due to the deposits forming on the cathode.

CORNELL UNIVERSTTY,

February, Igo4.

\section{RUTHENIUM, V. THE CHLORIDES (Continued).}

BY JAS. LEWIS HUWE.

Received March 17. 1904.

IN A previous paper upon the chlorides of ruthenium ${ }^{1}$ there were described cesium and rubidium chlorruthenates, $\mathrm{Cs}_{2} \mathrm{RuCl}_{6}$ and $\mathrm{Rb}_{2} \mathrm{RuCl}_{B}$, and a so-called cesium "aquo" chlorruthenate, but at that time little had been learned of the conditions of formation of these salts. While no light has been thrown upon the peculiar origin of the particular chlorruthenates described in that paper, further study has shown a general method by which the chlorruthenates, $\mathrm{X}_{2} \mathrm{Ru}^{\mathrm{IV}} \mathrm{Cl}_{6}$, as well as the "aquo" chlorruthenates, can be prepared.

When a solution of ruthenium trichloride, prepared by the action of hydrochloric acid on either ruthenium tetroxide or the hydrated sesquioxide (that is, the ordinary ruthenium chloride) is boiled in very dilute solution with hydrochloric acid and alcohol, it gradually changes from its deep yellowish red color to a lighter and less yellow tint. If now it is evaporated with an alkaline chloride, it deposits crystals which may vary from the rose prisms described in the previous paper, to rich red crystals, somewhat resembling the ordinary crystals of the chlorruthenite $\left(\mathrm{X}_{2} \mathrm{Ru}^{\mathrm{III}} \mathrm{Cl}_{5}\right)$, but lighter in color and transparent. This change may be induced by other agents than alcohol, as oxalic acid and possibly stannous chloride. These crystals are the "aquo" chlorruthenate, the cesium salt of which was described in the previous paper. Their formula is $\mathrm{X}_{2} \mathrm{RuCl}_{5} \mathrm{H}_{2} \mathrm{O}$, but to distinguish them from the ordinary hydrated salts of the chlorruthenites, the formula may be written $\mathrm{X}_{2} \mathrm{Ru}\left(\mathrm{OH}_{2}\right) \mathrm{Cl}_{5}$.

The "aquo" chlorruthenates differ very markedly from the isomeric chlorruthenites. They are stable to $140^{\circ}$, but lose water rapidly at $180^{\circ}$, leaving the salt $\mathrm{X}_{2} \mathrm{RuCl}_{5}$. Crystals of the dehydrated potassium "aquo" chlorruthenate preserve the form of the

1 'rhis Journal, 23, 775 (rgor). 